\title{
Landscape, memory and learning to change in changing worlds: Contemplating intergenerational learning and traditional knowledge practices within social-ecological landscapes of change
}

\author{
Rob O'Donoghue, Juan Carlos A. Sandoval-Rivera and Unnikrishnan Payyappallimana
}

\section{Preamble}

The core paper and collection of short papers from Mexico, Africa (Zambia and South Africa), India and Sweden that make up this study on social-ecological landscapes developed as a South-South collaboration that was extended to include a case in the North. Our concern was to explore how situated, intergenerational knowledge commonly takes a back seat to the conceptual propositions that the environmental sciences have developed around matters of concern like biodiversity loss. In this way, scientific propositions have become the conceptual capital for informing future sustainability through Education for Sustainable Development (ESD). In response to this, a more situated turn has developed to engage both intergenerational practices and the institutional sciences, but the playing fields are seldom level and deliberations are often rife with misunderstandings.

Current trajectories of social-ecological change were already evident at the turn of the 20th century where one found the colonial oppression of indigenous peoples and early manifestations of accelerating environmental degradation. The latter escalated into biodiversity loss as a global concern that both underpins and resonates with the current complex of global risks. This concern has shaped education imperatives towards learning-led change so as to reduce the risk of catastrophic problems such as climate change and ocean acidification, for example. These and other critical sustainability concerns have developed as planetary limits are being exceeded on a widening scale. The associated patterns of change and escalating risk in the modern era have played out in each of the regions where our teams of authors have researched their short papers on social-ecological change and intergenerational learning. The papers are intended as contributions that might better situate indigenous peoples on their intergenerational lands in reflexive learning within a rich mix of ancient and modern scientific ideas and ideals.

Each contributing team of writers offered to develop a short case study to illustrate how intergenerational patterns of practice have shaped long-term sustainable landscapes in their regions. We noted how much of the intergenerational knowledge was marginalised during colonial modernity, which generally denigrated and discounted the knowledge of the oppressed against the dominant institutional hegemonies and the omnipotent objectivity of the sciences. To inform our work, we loosely drew on the 'history of the present' processes of Tom Popkewitz (1988), who points to how education imperatives to change The Other developed in ways that 
did not consider how: 'The identification of culture in pedagogy is never free-floating but occurs in a context of power relations' (1988:80).

The opening core paper explores issues of knowledge and power and the case study papers from Mexico, Africa, India and Sweden that follow each exemplify implicit knowledge practices. These have shaped intergenerational landscapes that have been radically transformed within colonial modernity and the marginalising expansions prevalent in recent globalising trajectories. Each of the papers opens up some of the contours of intergenerational knowledge practices to explore how indigenous custodians of the associated knowledge are implicated in patterns of practice that have shaped landscapes over time. Against these, the attendant contradictions emerging in modernist globalisation and reflected in the Sustainable Development Goals (SDGs) cannot simply be read using expert analysis or be contemplated against global ideals generated with the abstract concepts of the environmental sciences. The depth of historical wisdom and its intergenerational custodians must enter the sustainability game as key players towards attaining more just and sustainable futures.

In contrast to the concerns and perspectives that one commonly finds in ESD, people engaged in intergenerational learning are foregrounded here along with what they know and what is going wrong in the world around them. This approach to reflexive learning invites intergenerational story sharing as a starting point for raising concerns and for engaging with useful knowledge that modern sciences generate to help us steer our continuing learning towards future sustainability. It also shapes the somewhat unusual approach to this collection of papers.

The core paper opens with a provocative statement borne of a decolonial perspective (Maldonado-Torres, 2007) that sees abstractions within the Arcadian idealism underlying the ecological sciences as not adequate against the intergenerational nuance of situated cultural practices. It addresses these questions in terms of the sophistication that intergenerational accounts and social-ecological perspectives can bring to learning alongside the object congruent knowledge and risk surfaced by modern environmental sciences. A Post Script explores touchstones on situated competence, deliberative learning and ESD as co-engaged processes of learning-led change.

Around these insights and standpoints, the papers assembled through collaboration invite us to contemplate traditional ecologies of knowledge and intergenerational action learning within social-ecological landscapes of change.

\section{Abstract}

This study contemplates the interweaving of knowledge practices within social-ecological landscapes of change. In doing so, it takes a position that indigenous peoples should not be too readily enticed into being identified as traditional custodians of nature within western ecological abstractions when they have their own histories as intergenerational creators of, and curators in, mosaic landscapes of biocultural diversity. The review explores how traditional social-ecological knowledge has seldom been explored as integrated within seasonal cycles or as ecologies of knowledge ${ }^{1}$ that have shaped social-ecological landscapes in diverse biocultural regions. Here, key aspects of the intergenerational cultures embedded in long-term sustainability practices have shaped and sustained social-ecological landscapes into the era of modern capital. The core 
paper that follows proposes that exploring the intergenerational knowledge practices implicit in local cultural landscapes can be a key positive dimension for shaping learning-led change in a modern era of widening environmental degradation and biodiversity loss.

Five short case study papers are coupled with this study. They reflect some of the dimensions of intergenerational ecologies of knowledge that are evident within biocultural mosaic landscapes in:

1. Mexico (Zongolica, Sierra Grandes Montañas - milpa);

2. Zambia (Miombo Woodland - chitemene);

3. South Africa (Zululand savannah grasslands - Nguni cattle);

4. India (Western Ghats monsoon forests - sacred grove rice-lands);

5. Sweden (Vattern Scarp - meadow pastures).

The narratives were compiled as brief case studies at the intergenerational landscape level in each of the countries. Each case narrative is situated with a photograph of the macro landscape and with a photo of the intergenerational heritage practices that have had shaping effects within the social-ecological landscape in question. The case materials point to insights that have the potential to enable restorative and re-imagining possibilities for future sustainability. The short case studies locate people and their intergenerational practices in relation to modern landscapes of change. Here the writers reside as dialogical partners working in more inclusive and reflexive learning-led change. Some dimensions of the intergenerational practices that have been sustainable over generations have been implicated in modern patterns of change that have become drivers of environmental degradation in the modern era. However, much of the indigenous common sense is commonly overlooked.

The case studies are intended to open up and refine social-ecological insights in relation to the complex intergenerational relational dynamics amongst cultures and landscapes.

[W] hat could be legitimately asked is to what extent some kind of 'practical' abstraction, conceived of as a strategy of generalisability and an experience of interconnectedness, is actually needed for emancipatory anti-capitalist politics to counter the divisive and singularising instances that proliferate in the camp of the oppressed. (Muscat, 2011:43)

\section{Background}

In our interacting work of the last few years, we have visited numerous sites where cultural practices have been situated in, and have shaped, social-ecological landscapes over many hundreds of years. These landscapes were also undergoing rapid change that accelerated with modernity to threaten future sustainability of both indigenous cultural capital and the landscapes sustaining this. It struck us that there was much to be learned across the cultures involved and the modern ecological sciences that were increasingly being used as a source of concepts and perspectives to assess degradation and to call for learning-led change to reverse current cycles of environmental disruption and decline.

The experiences that brought us together as a writing team were diverse. Rob O'Donoghue was inspired by the works of Erach Bharucha (2016,2017), which explored the diverse cultures 
and landscapes of India. These elevate situated and scientific knowledge to the landscape level and raise open questions about learning-led change and future sustainability.

Juan Carlos A. Sandoval-Rivera is developing a research programme inspired by fieldwork where the cultural capital of indigenous peoples and the ecological sciences interact in the generation of new knowledge for informing future sustainability. Here he is working with the indigenous research agenda after Linda T. Smith (1999) that is orientated to the selfdetermination of indigenous peoples. He has noted an affirming and deepening of traditional knowledge practices especially where knowledge systems were deployed in collaborative learning at the nexus of local concerns.

When Unnikrishnan Payyappallimana asked us to explore these ideas in print, we decided to work with him and invited multi-site writing teams to participate so that the landscape-level cases examined might provide insights into the co-shaping of cultures and landscapes over many generations. This study and the collection of short case study papers is an attempt to open up conversations that might inform and expand the scope of ESD as co-engaged meaning-making at the level of future landscapes for human flourishing.

A tension shaping the impetus to develop this paper was a realisation that the ecologies of conservation science and the ecologies of knowledge in traditional intergenerational settings have seldom interacted on a relatively level playing field. A recent advance has been the instituting of 'participatory mechanisms' in the Convention on Biological Diversity and the Intergovernmental Panel on Climate Change (IPCC). It is notable how the Scientific Advisory Board of the United Nations has recently made policy decisions that

recognize Indigenous and Local Knowledge(s) as complementary to Science(s) and integral to knowledge-policy platforms on sustainable development, biodiversity and climate change. (UNESCO, 2016:1)

The concepts and perspectives of environmental sciences have been dominant in framing the concerns and steering the international environment and sustainability agendas; intergenerational indigenous perspectives have seldom been prominent beyond a recognition of the need for social justice. We hope that this study and the writings from Mexico, India, Zambia, South Africa and Sweden will exemplify how knowledge in ongoing generative movements that Ingold (2010) notes are at once 'itinerant, improvisatory and rhythmic' emerges as generative processes of intergenerational innovation. The gaze of the review is thus centred on intergenerational knowledge contexts to exemplify how a plural capital of situated social-ecological knowledge is foundational in reflexive learning to reimagine more sustainable futures together.

\section{Traditional ecologies of knowledge}

As environment and sustainability problems emerged within the accelerating trajectories of consumption in the modern age, it became popular to inscribe indigenous peoples as custodians of nature. In early environmental education in southern Africa, for example, this role was 
ascribed to the Bushmen, the first nations San peoples, and also to the Khoi-speaking peoples of southern Africa (O’Donoghue, 1998). Ironically, indigenous peoples of Nguni origins were initially bracketed out. Would these early peoples have agreed on the notions of ecological harmony and holism that they were said to pass down from generation to generation?

As the role of situated cultures as custodians of traditional ecological knowledge was extended to many indigenous peoples all over the world, some entered the conversation, but many also experienced intractable contradictions. A double-bind paradox in southern Africa was that indigenous peoples were doomed to fail in the nature-centred discourses of ecological sustainability. If they gave up lands to conservation, they seldom had adequate access and skills to manage the international tourism economies that were to provide alternative income streams. Here their cultures became either performative for the entertainment of others or were lost against the ecological idealism of natural wonders devoid of, or set against, the excesses of human exploitation. The conservation and tourism economies were also tenuous and fragile given the footprint of global recreational travel along with the associated health and safety considerations that set the tourist apart. If indigenous communities did not buy into setting aside conservation lands, then their patterns of ecological consumption were commonly excluded by colonising laws framed around the economic self-interests and the Arcadian ideals of the colonising nations and environmental management regulations.

This study sought to avoid the paradoxes of Arcadian ecological idealism and clear the ground so as to open up the prospect of co-engaged meaning-making at the landscape nexus of traditional social-ecological knowledge practices and modern environment and sustainability science knowledge. To begin these conversations towards learning-led change for transitioning to future sustainability, the paper concludes by giving attention to the possibility of increased learning at the nexus of landscape and intergenerational heritage practices.

\section{The emerging ecological legacy of the natural sciences}

Latour (1999), in his Pandora's hope, illustrates how scientific environmental knowledge was constituted as 'time saving abstractions' within circular dialogical processes between laboratory and field. The abstracted concepts developed were useful to those privy to the emerging symbolic capital that enabled participants to signify reality and to predictively model and agree on explanatory insights in relation to the workings of natural systems and processes. In this way, scientist observers were able to constitute new environmental knowledge about nature and to begin to use an increasingly object-congruent capital to resolve emerging matters of concern.

Shava (2008) illustrates how much of the early explanatory capital in the natural sciences in Africa initially drew on knowledge-sharing interactions with indigenous peoples. The indigenous people were then seldom privy to the scientific concepts developed within the prevailing colonial perspectives. Here, knowledge was accumulated in a foreign language and was constituted as disciplinary fields that came to be held in, and dispensed from, modern scientific institutions. In this way, new scientific knowledge was usefully accumulated as realitycongruent perspectives within disciplinary fields in scientific institutions and was increasingly 
put to use in the expert reading of concerns and in the development of propositions for the resolution of conservation and sustainability problems.

The ecological sciences were thus deployed and developed in the explanatory modelling of risk. This reflexively made human-induced environmental degradation more explicit to experts. Widening environmental change and deeper expert insights into how humans were impacting natural surroundings began to give rise to calls for education to create the necessary awareness of the impacts of human activities so that new and more sustainable patterns of practice might be developed.

This process account of knowledge relations between indigenous peoples and the natural sciences serves to illustrate how the production and control of a useful kind of realitycongruent knowledge became vested in the modern sciences of the state. It also illustrates how the accumulating knowledge was constituted within particular patterns of control and through the exercise of state power and the ideals of the times. The ideals in many African contexts of colonial expansionism were those of Sylvain harmony in nature (Sharma, 1995) and an appropriating control of land and its resources ${ }^{2}$ by capital.

As a response to increasing state hegemonies, Kincheloe and Steinberg (2008) point to the need for the inclusion of indigenous knowledge as a way to counteract the destruction of the planet that the western sciences have shaped. They note that indigenous knowledge can help to counteract the current poly-crisis because of its focus on the relationships that exist between human beings and their ecosystems. This aspect has, until recently, been absent in much of the knowledge produced within the empirical canons of western science.

The dialogue between scientific knowledge and indigenous knowledge requires recognition of the existence of indigenous cultures as producers of valid knowledge that has been constituted over generations but seldom in dialogue with western knowledge. In this sense, in order to foster a dialogue like the one mentioned, it is necessary to identify the 'cultural pedagogies' (Kincheloe \& Steinberg, 1999) at play shaping situated knowledge practices and to contemplate these as processes of intergenerational knowledge production that have shaped livelihood practices and landscapes over time. Intergenerational 'cultural pedagogy' refers to

education that takes place in a variety of social settings, including, but not limited to, school. In our opinion, if we want to make sense of race, social class, and gender and their relationship to the socio-educational process, our work as cultural and educational scholars requires that we study, in addition to school, the cultural pedagogy that takes place outside of it. (Kincheloe \& Steinberg, 1999: 32-33)

It is possible to note how the relational dynamics and ideals of colonial modernity took little note of these and education has generally functioned within patterns of exclusion that were centred on enabling access to the propositional knowledge of academic subjects. The histories of colonial knowledge appropriation and marginalisation established the ground rules for modern education and an emerging assumption that the scientific drivers of modernism could be reversed through the deployment of ecological reasoning in environmental education. The history of knowledge appropriation and the exclusions here are a necessary backdrop for 
contemplating a return of indigenous custodians of the land and the prospect of restorative effects where intergenerational knowledge practices and scientific knowledge are co-mingled.

\section{The co-mingling of heritage practices of humans and environmental sciences}

The study notes that although the environmental sciences have expanded to the landscape level, these are still often underpinned by Sylvain idealism (Sharma, 1995) that has commonly bracketed out human interactions as integral to nature and biodiversity. Ecological narratives in Africa and elsewhere have commonly positioned indigenous peoples on the margins in an exclusionary, globalising modernity and as a key part of the problem shaping biodiversity loss. This perspective has a reality congruence for probing how the expansionism of the modern era has transformed landscapes. It unfortunately often downplays or excludes a human role in the biodiversity of the planet. In recent years, the limitations of the early ecological sciences have been transcended and indigenous peoples are being included in conservation practices, but this commonly happens such that their re-inscription is mediated through the lens of ecological harmonies rather than with a more realist grasp of human co-existence within the malleable seasonal dynamics and resilience of landscapes as biocultural entities. Overlooked also are the historical processes of exclusion, expropriation and exploitation that indigenous peoples have suffered for more than five hundred years and which have shaped the over-exploitation of natural resources for marginalised rural communities to survive.

As the ecological and environmental sciences have recently been reconstituted as sustainability sciences, much of the education work in southern Africa and elsewhere is still drawing on ecological idealism borne of visits to protected areas such as parks, and the notion that humans are disruptors of past natural system harmonies. Challenges to this hegemony are notable in the Southern African Development Community (SADC) region (see Mukute, Marange, Masara, Sisitka \& Pesanayi, 2012), but there are few education materials and activities that include indigenous peoples and social-ecological evidence of how cultures and landscapes are co-shaped over time (see Boege, 2008; Burger, 1987; Toledo \& Barrera-Bassols, 2009). Insights on colonialism and early indigenous knowledge practices are essential for a grasp of how humans have come to exceed the sustaining resilience of planetary systems and to invite conversation towards balancing adjustments in how we live and do things in the world.

Reynar (1999) proposed that, for a better understanding of the complexity of the world, the more perspectives we can take into account, the better we will be able to mediate our understandings of reality. In this sense, different frames of reference produce multiple interpretations and enable us to contemplate multiple realities. A multilogical epistemology and ontology fosters a distancing from the real, enabling us to contemplate different frames of reference. Starting from this assumption, in the relations between actors coming from different cultural fields can be found complex matrices of interaction, codes and meanings that are taken up in dialogue to inform our understandings. As an example, we have critical pedagogy affirming that there are no simple or privileged ways of seeing the world, not only one way to represent the world artistically, nor a single way to teach science or write history (Jaramillo \& McClaren, 2008). In the educational field, once teachers escape the traps of the 'keeper 
positivism of the western tradition' (Kincheloe \& Steinberg, 2008:139), simplistic thinking, which can be represented by a two-dimensional photograph, is replaced by the multiple angles of a holographic photograph. Stimulated by this 'cubist cognition', educators can understand that the teaching models they have used, the research definitions they have been handling, the vision from which they have been instructing, as well as the learning modes they have been forming, are nothing more than a particular knot in the network of reality (Kincheloe \& Steinberg, 2008). The possibility of observing reality critically from a multilogical perspective allows a form of analysis that fosters connections and attends to the context. The conceptions derived from the perspective of the historically excluded make it possible to visualise the power of difference, the processes of oppression and the limitations of the monocultural ways of constructing meanings (Reynar, 1999).

The illustrative case studies that follow are an attempt to explore some of the landscapelevel histories of a co-evolution of people and planet. They are intended as starting points to invite conversations that explore the relational dynamics between human practices and evolving landscapes in diverse and interesting parts of the world. They are also done in ways that intermesh the intergenerational knowledge practices of indigenous peoples and the accumulating capital of modern environment and sustainability sciences together to open up pathways for re-imagining futures that are more just and sustainable within a deepening grasp of the resilience of natural systems and processes in a changing world.

These dimensions came to the fore on a recent visit to Norway, when Rob O'Donoghue met Sven Poulson, a landscape and calendar artist whose creative work depicted the mountain cultures of Norway within the seasonal cycles of the Hardangervidda. His work allowed us to frame our work on social-ecological systems and elevated our thinking to contemplate landscape, people and the seasonal cycles that integrate cultural practices and the natural world as interpenetrating processes over many generations.

Figure 1. Sven Poulson and his depiction of the seasonal cycles of the Hardangervidda
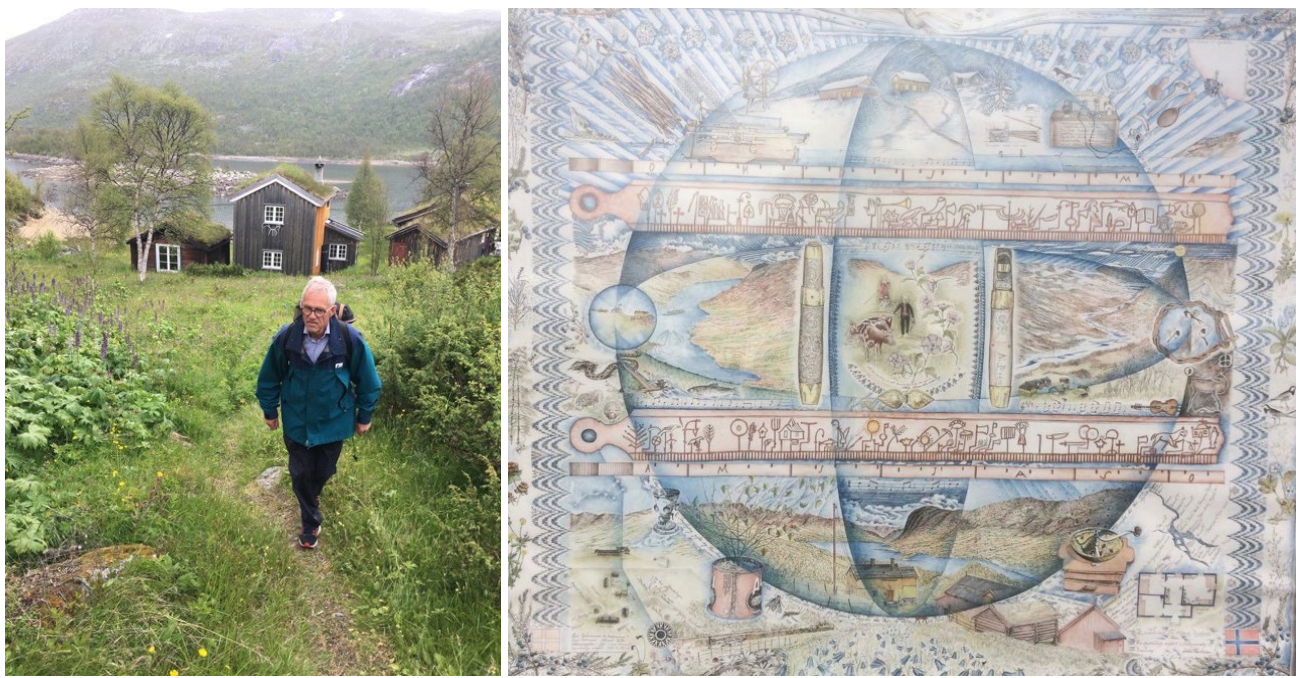
The social-ecological dimensions of his work resonated with the seasonal cycle calendars of Mexico and the monsoon cycle of the Western Ghats. Rob had the pleasure of working with Juan Carlos and being introduced to the intergenerational knowledge practices related to the milpa of Zongolica (Case study 1) with Citlalli, Belinda, Fortunata, Helio and Mark earlier that year. A few years prior to that, Rob had visited the sacred groves of the Western Ghats (Case study 4) as well as experiencing the Vattern Scarp landscapes of Sweden (Case study 5). In recent work on climate change, he was introduced to the long-term chitemene in Zambia (Case study 2) after earlier having conducted his $\mathrm{PhD}$ on the conservation practices of Zululand in South Africa (Case study 3). The cases thus self-selected out of the experience of working with leading environment and sustainability educators learning in local environments in co-engaged ways.

Our shared experiences and the substance of these cases pointed to common ground in learning interactions, namely how people and landscape 'spoke to each other' revealing many generations of sustaining practices that have been disrupted in colonial modernity around the world. Here, our common interest in education and learning-led change pointed to the importance of integrating ecological perspectives with intergenerational knowledge practices in learning with custodians of traditional ecological knowledge who are working the land in reflexive ways in times of change.

\section{Endnotes}

1. Interdependent cultural dispositions and social-ecological practices developing over many generations. See De Sousa Santos (2007) on 'ecologies of knowledges'.

2. There are attempts such as the community protocols and biocultural protocols, which are newly emerging positions within the global policies against this state control. See https:// www.cbd.int/abs/text/articles/default.shtml?sec=abs-12

3. Custodianship here implies both an intentional shaping purpose and a more blind mediator of desired effects. It is notable how the Nguni burning practices served to both create cattle lands and exclude the risk of wildlife or how the sacred forests of the Western Ghats conserved water and provided nutrients to rice plants. Both of these were clearly intended in the indigenous knowledge practices in each case (examined later) that had landscape effects sustained over time and within the seasonal cycles.

\section{About the authors and their contributions}

\section{Lead author}

O’Donoghue, Rob

Environmental Learning Research Centre (ELRC), Rhodes University, South Africa r.odonoghue@ru.ac.za

Rob O'Donoghue is an Emeritus Professor at the ELRC at Rhodes University. In his research on environmental education processes of learning-led change, he has given close attention to indigenous knowledge practices, social theory and environmental learning in post-colonial curriculum and community contexts. 


\section{Co-author}

Sandoval-Rivera, Juan Carlos A.

Instituto de Investigaciones en Educación, Universidad Veracruzana, Mexico

ORCID 0000-0001-8084-282X | jcsandoval.rivera@gmail.com

Juan Carlos A. Sandoval-Rivera is based at the Instituto de Investigaciones en Educación, UniversidadVeracruzana in Mexico.Through audio-visual collaborative research methodologies, the author researches and supervises educational research projects on the interaction between indigenous knowledge and scientific knowledge in socio-ecological processes and the adaptation to climate change in indigenous contexts.

\section{Co-author}

\section{Payyappallimana, Unnikrishnan}

United Nations University-International Institute for Global Health, Kuala Lumpur, Malaysia payyappalli@unu.edu

At the time of contributing to this paper, Dr Unnikrishnan Payyappallimana was working at the United Nations University Institute of Advanced Studies based in India. He currently works at the United Nations University-International Institute for Global Health, Kuala Lumpur. His main research interests include traditional medicine in health systems, public health, medical pluralism, traditional knowledge epistemology, science-policy interface and sustainable development.

\section{Percentage contributions}

\begin{tabular}{|l|l|l|}
\hline Areas of contribution & Authors & $\begin{array}{l}\text { Percentage } \\
\text { contribution }\end{array}$ \\
\hline \multirow{3}{*}{$\begin{array}{l}\text { Conception or design of the paper, theory } \\
\text { or key argument }\end{array}$} & O'Donoghue & $50 \%$ \\
\cline { 2 - 3 } & Sandoval-Rivera & $25 \%$ \\
\cline { 2 - 3 } & Payyappallimana & $25 \%$ \\
\hline \multirow{5}{*}{ Data collection } & O'Donoghue & $50 \%$ \\
\cline { 2 - 3 } & Sandoval-Rivera & $25 \%$ \\
\cline { 2 - 3 } & Payyappallimana & $25 \%$ \\
\hline \multirow{5}{*}{ Analysis and interpretation } & O'Donoghue & $50 \%$ \\
\cline { 2 - 3 } & Sandoval-Rivera & $25 \%$ \\
\cline { 2 - 3 } & Payyappallimana & $25 \%$ \\
\hline \multirow{5}{*}{ Drafting the paper } & O'Donoghue & $50 \%$ \\
\cline { 2 - 3 } & Sandoval-Rivera & $25 \%$ \\
\cline { 2 - 3 } & Payyappallimana & $25 \%$ \\
\hline
\end{tabular}




\begin{tabular}{|l|l|l|}
\hline Areas of contribution & Authors & $\begin{array}{l}\text { Percentage } \\
\text { contribution }\end{array}$ \\
\hline \multirow{2}{*}{ Critical review of paper } & O'Donoghue & $50 \%$ \\
\cline { 2 - 3 } & Sandoval-Rivera & $25 \%$ \\
\cline { 2 - 3 } & Payyappallimana & $25 \%$ \\
\hline
\end{tabular}

\section{References}

Bharucha, E. (2016). Living bridges: Folk cultures of India, then and now. Uttar Pradesh: HarperCollins.

Bharucha, E. (2017). Changing landscapes:The cultural ecology of India. Uttar Pradesh: HarperCollins.

Boege, E. (2008). El patrimonio biocultural de los pueblos indígenas de México Hacia la conservación in situ de la biodiversidad y agrodiversidad en los territorios indígenas. México, D.F.: Instituto Nacional de Antropología e Historia, Comisión Nacional para el Desarrollo de los Pueblos Indígenas.

Burger, J. (1987). Report from the frontier: The state of the world's indigenous peoples. London: Zed Books.

De Sousa Santos, B. (2007). Beyond abyssal thinking: From global lines to ecologies of knowledges. Review, XXX(1), 45-89.

Ingold, T. (2010). The textuality of making. Cambridge Journal of Economics, 34, 91-102.

Jaramillo, N. \& P. McLaren, P. (2008). Rethinking critical pedagogy: Socialismo Nepantla and the specter of Che. In N.K. Denzin, Y.S. Lincoln \& L.T. Smith (Eds), The handbook of critical and indigenous methodologies (pp. 191-210). Thousand Oaks: SAGE.

Kincheloe, J.L. \& Steinberg, S.R. (1999). Repensar el multiculturalismo. Barcelona: Octaedro.

Kincheloe, J.L. \& Steinberg, S.R. (2008). Indigenous knowledges in education: Complexities, dangers, and profound benefits. In N.K. Denzin, Y. S. Lincoln \& L.T. Smith (Eds), The handbook of critical and indigenous methodologies (pp. 135-156). Thousand Oaks: SAGE.

Latour, B. (1999). Pandora's hope: Essays on the reality of science studies. Cambridge, MA: Harvard University Press.

Mukute M., Marange T., Masara, C., Sisitka, H, \& Pesanayi, T. (2012). Future capacity building: Assessment for environmental policy implementation. Howick: SADC REEP.

Muscat, J. (2011). Hegel and the advent of modernity: A social ontology of abstraction. Radical Philosophy, 2(1), 29-46.

O’Donoghue, R., Shava, S. \& Zazu, C. (2013). African heritage knowledge in the context of social innovation. Yokohama: United Nations University Institute for Advanced Studies (UNUIAS).

Popkewitz, T. (1988). Culture, pedagogy and power: Issues in the production of power and colonization. Journal of Education, 170(2), 17-90.

Reynar, R. (1999). Indigenous people's knowledge and education: A tool for development. In L. M. Semali \& J.L. Kincheloe (Eds), What is indigenous knowledge? Voices from the academy (pp. 285-304). New York: FalmerPress.

Sharma, S. (1995). Landscape and memory. London: HarperCollins. 
Shava, S. (2008). Indigenous knowledges: A genealogy of representation and applications in developing contexts of environmental education and development in southern Africa. Unpublished PhD Thesis, Rhodes University, Grahamstown, South Africa.

Smith, L.T. (1999). Decolonizing methodologies: Research and indigenous peoples. New York: Zed Books.

Toledo, V.M. \& Barrera-Bassols, N. (2009). La memoria biocultural la importancia ecológica de las sabidurías tradicionales. Barcelona: Icaria Editorial.

UNESCO (United Nations Educational, Scientific and Cultural Organization). (2016). Indigenous and local knowledge(s) and science(s) for sustainable development. Policy Brief by the Scientific Advisory Board of the United Nations Secretary-General, 5 October 2016. 
Case study 1: Mexico

Zongolica, Sierra Grandes Montañas - milpa and forests

Citlalli López-Binnqüist, Belinda Contreras-Jaimes, Fortunata Panzo-Panzo, Helio García-Campos and Mark K. Stowe

Figure 2. Landscape with patches of pasture, forest, pine plantations and milpa.

Figure 3. Harvest of maize - part of the

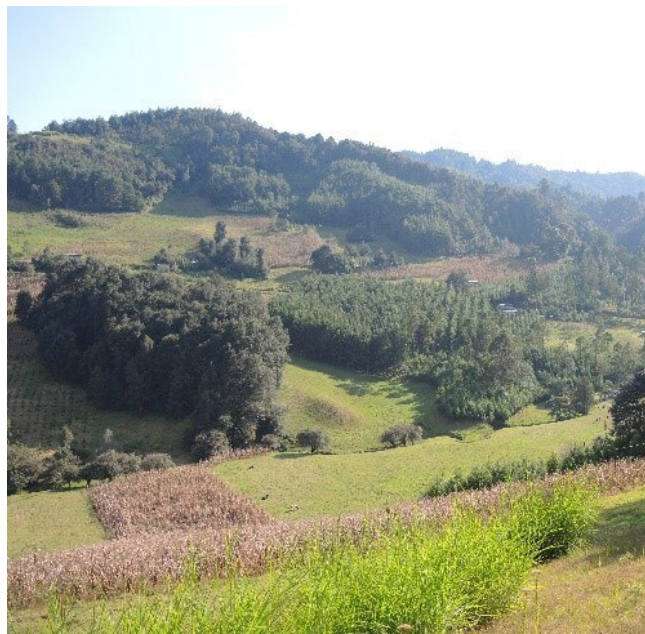
management of milpa.

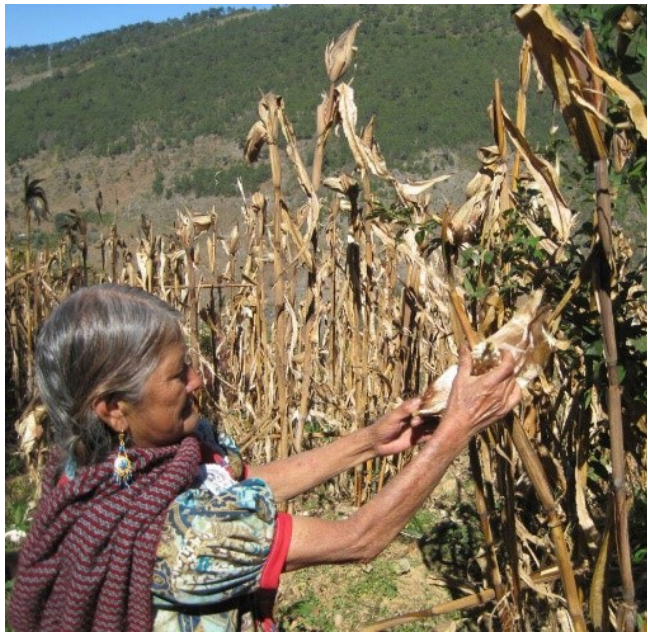

Source: Belinda Contreras-Jaimes

Source: Fortunata Panzo-Panzo

Figure 4. Offerings in the milpa.

Figure 5. New types of diversified

Intergenerational heritage practices.

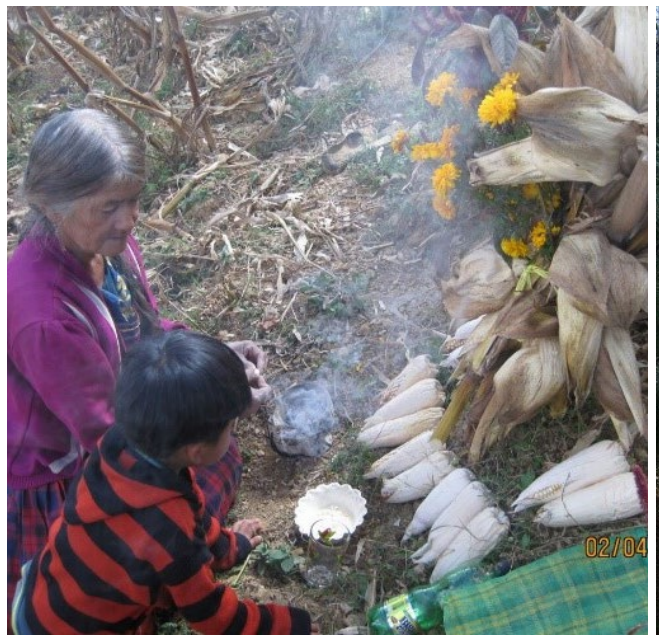

management - interspersing maize and pine.

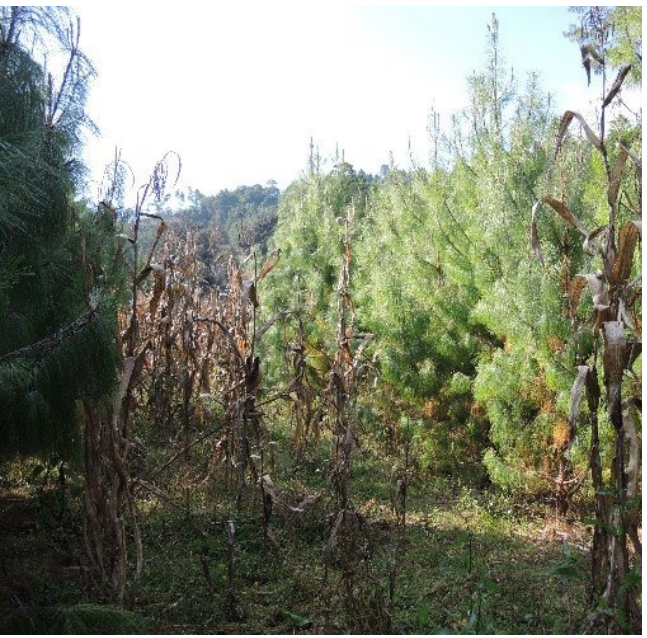

Source: Fortunata Panzo-Panzo

Source: Belinda Contreras-Jaimes 
The Sierra de Zongolica is a mountain range inhabited since pre-Hispanic times by Nahua people. The current population includes 200000 speakers of the Nahuatl language, and it is a region with a strong indigenous cultural identity. Known locally as 'the Great Mountains', the dramatic karst landscape ranges in altitude from 500 to $3000 \mathrm{~m}$ above sea level. The region can be divided into three zones: warm (lowest), temperate and cold (highest). The cold zone, (Tlasesekya in Nahuatl), where this case study is located, is a mosaic of various intensities of human use, including pine-oak ecosystems in different successional stages, pasture patches for sheep grazing, pine and mixed crop plantations, and housing areas.

These agro-forestry systems are based on a fine understanding of the management of vegetation in different growth and regeneration cycles. Maize (Zea mays) was domesticated in central Mexico and constitutes the most significant and emblematic Mexican biocultural heritage. For thousands of years, it has been the mainstay of agriculture in Zongolica. This grain is grown in a traditional system of production known as milpa, which cycles between maize, squash and beans, and includes the management of weeds, trees and fauna. It depends on letting the land rest for regeneration and using short or long production cycles with a diversity of perennial and annual managed species that include domesticated species, cultivated wild species, and tolerated (and then harvested) weeds. The management of the milpa constitutes a body of practices, knowledge and spirituality that has been transmitted through the generations to this day.

Milpa involves 'tillage and burning', which makes it a form of transhumance (shifting cultivation) agriculture. Because of this, the forest and the spaces dedicated to agriculture in vast regions of the Eastern Sierra of Mexico maintain a delicate balance, with a hydrological cycle that shows significant resilience.

Historically the use of various timber and non-timber forest resources has been a part of Nahua daily life, providing food, dyes for textiles, fuels, medicines, and more. The commercial exploitation of wood for sale as a raw material or transformed into rustic furniture (the main timber product of the region) is a more recent practice. Commercial timber harvesting emerges as a practice distinct from local management traditions, one heavily influenced by external agents and market forces, but also adapting to coexist with the local ways of life.

Two historical events resulted in excessive extraction of wood with an impact on the forests of the region. The first was the Second World War, and the second arises from a national policy that allowed logging concessions and open access without regulation for the extraction of wood as a raw material for railways and mines. The abuses that resulted from this policy led to a total ban on logging in most of the mountain forests in Mexico. But this ban was not enforced in Veracruz, Huasteca or Zongolica, leading to intense clandestine deforestation (often accompanied by violence) conducted by intermediaries from outside the Sierra.

It was thanks to the mobilisation of the Nahua population that control over the forests was regained. Subsequently, various government initiatives, including commercial programmes of pine plantation and reforestation with Pinus patula have been carried out. These programmes have impacted the management of family plots and the landscape - with wood as a source of household income sometimes beginning to compete with maize. In the face of this, in an innovative manner and as an expression of resistance and resilience, the peasants are exploring 
ways to maintain the milpa by integrating in them the growth cycles of pines and other useful trees and plants. This allows the generation of income and various products for selfconsumption. Unfortunately, it has also led to a decrease in biodiversity - since the government does not favour local cultural values and the growth of native trees that have more uses. On the other hand, the inhabitants have noticed and appreciated the environmental benefits that have come from increased forest cover, including the decrease of erosion leading to fewer landslides and the restoration of springs. Thus, the landscape reflects tensions and compromises as the peasants use their detailed knowledge of the biophysical conditions to maximise their resources.

In this way, local interest in the cultivation of milpa, with its great cultural roots and accumulated millennia of experience and knowledge, is colliding with modern forestry practices, many coming from government initiatives that are not linked to traditional management. This results in new knowledge and innovation, but also the loss of local knowledge when traditional products and their production techniques are displaced. These practices may follow the traditional ways of transmitting knowledge, namely through observation, orality and practice. But this transmission will no doubt be reinvented in the context of school education, globalised communication and the cultural influence of migrants.

This reflection encourages critical questioning and uncertainty about change, especially in the face of a growing gap between local and school knowledge, and in the face of migration, fragmentation of the landscape and external markets. This greater pressure affects a region with a great need as well as great potential for conservation of water and biodiversity, among other resources. This situation highlights the vulnerability of the Nahuas and, at the same time, highlights their ability to adapt.

\section{About the authors}

The authors of this case study are part of a transdisciplinary group called Grupo de Manejo Integral de los Montes de la Sierra de Zongolica (MIMOSZ), which was formed in 2010. Their backgrounds are in anthropology, communication, intercultural management and biology. Mainly associated with the UniversidadVeracruzana, they have extensive experience in research, teaching and participatory community processes. Their work is linked locally to peasantbased organisations and civil and citizen organisations and internationally to diverse networks, especially People and Plants International.

The group works on the strengthening of local organisations and the conservation of biocultural heritage. They work towards these goals by training local university students and community groups in regional planning, community forest management, handicrafts, environment, agriculture and food sovereignty. They work at the intersection of language, landscape and knowledge transmission.

\section{Bibliography}

Alatorre-Frenk, G., López-Binnqüist, C. e Hidalgo-Ledesma, R. (2014). Campesinado forestal en la sierra de Zongolica, Veracruz: Sujetos políticos en construcción y formas de organización social en torno al kohyo o monte. Memoria del IX Congreso Internacional de Sociología Rural Asociación Latinoamericana de Sociología Rural ALASRU México, D.F. 
Contreras-Jaimes, B. (2015). Reconocimiento del valor biocultural de la producción artesanal a través del intercambio de saberes. El caso de los textiles de lana en Tlaquilpa, Veracruz. (Tesis de maestría). Xalapa, México: Universidad Veracruzana.

Contreras-Jaimes, B., Panzo-Panzo, F. y López-Binnqüist, C. (2018). ArteSano: Autogestión del Kualli nikah, el "estado de estar". En Encina, J., Urteaga, E. y Ezeiza, A. (editores), Autogestión cotidiana de la salud.Volapük Ediciones, A.C., Seminario de Ilusionistas Sociales de la Universidad del País Vasco, UNILCO-espacio nómada, Universidad Libre para la Construcción Colectiva, Colectivo de Ilusionistas Sociales. Guadalajara, España.

López-Binnqüist, C., Negreros-Castillo, P. y de la Hidalga-Ledesma, V. (2014). Colaboración e intercambio de saberes en torno al manejo campesino de árboles maderables en la Sierra de Zongolica, Veracruz. Memoria del IX Congreso Internacional de Sociología Rural Asociación Latinoamericana de Sociología Rural ALASRU México, D.F.

López-Binnqüist, C., Contreras-Jaimes, B. y Sosme-Campos, M.A. (2014). Los textiles de la Tlasesekya: cuentos sobre hilos, telares y vellones. México: CITRO/ PPI/MIMOSZ/Overbrook. 


\section{Case study 2: Zambia}

\section{Chitemene agriculture}

Overson Shumba and Felix Kanungwe Kalaba

\section{Ecological setting}

It is important to start with an appreciation of the ecological setting in which chitemene is practised. The region covers approximately 2.4 million square kilometres of southern, central and eastern Africa where Miombo woodlands predominate. The habitat is characterised by highly weathered and leached forest soils where most of the nutrients are held in the vegetation and humus. The available nutrients are also generated by leguminous trees and shrubs that predominate and serve to fix nitrogen in the soil. The region in which these soils and woodlands are located coincides with Ecological Region III in Zambia, where the climate is tropical with in excess of $1000 \mathrm{~mm}$ average annual rainfall. The Miombo woodlands are thus characterised by having low acidity ( $\mathrm{pH} 4.0-4.5)$, low soil nutrient levels, low carbon exchange capacities and low levels of exchangeable or extractable nitrogen and phosphorus. As such, the soil is infertile and unsuitable for crop farming. It has required ingenuity for people living in these lands and forests to eke out a living through subsistence agriculture.

Figure 6. Today trees are cut both in chitemene agriculture and for charcoal production. Bottom right shows a kiln for curing cut logs for charcoal.
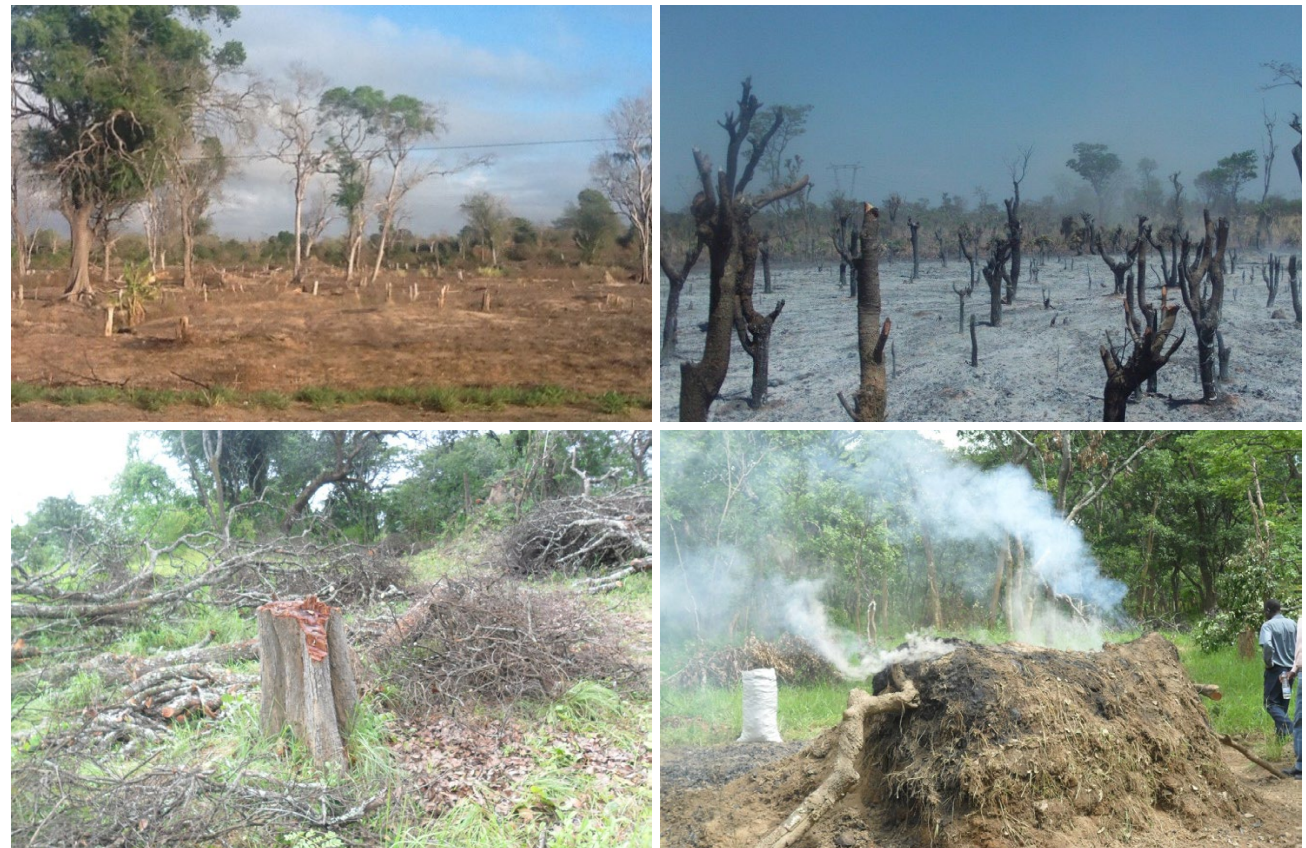

Source:Top row: http://cop21.uniceffrr/mapping/chitemene-traditional-farming-system/. Bottom row: Authors. 


\section{Chitemene cycle}

It is in such an ecological setting that the woodland-based agricultural system of chitemene is practised in the northern provinces of Zambia and in southwestern Tanzania, where the same practice is called ntemele (Grogan, Birch-Thomsen \& Lyimo, 2013). Chitemene (meaning to cut) is a shifting cultivation system in which the cultivators burn the cut biomass and then plant crops in the ashen remains. Essentially, chitemene follows a cycle. First, the plot in the woodland for crop farming is identified. Second, the branches of trees are lopped leaving the trunk standing. In its original form, the cut branches and leaves are dragged and piled carefully in the infield area at the centre of the field where they are left to dry. Just before, or at the onset of, the rainy season in October/November, the piles of branches and leaves in the infield are burned, leaving a layer of ash covering the soil (Chidumayo, 1996). Finally, crops are then planted in the ashen infield areas.

This infield area is the garden in which crops are planted for the next three to five years after which the plot is left to lie fallow for a period of up to 25 to 30 years. Grogan, BirchThomsen and Lyimo (2013) describe how the fallow period has shortened over several decades due to increasing population pressure, i.e., 25 to 30 years in the 1950s and 1960s, 15 years during the 1970s, ten years during the 1980s-90s, and three to seven years by 2010 . In the traditional chitemene, crop cultivation followed a pattern. The cropping started with finger millet intercropped with cassava in the first year, then followed by groundnuts in the second year and beans in the third year when cassava planted in the first year is harvested. The intergenerational knowledge and technology of the chitemene cultivators evolved out of careful observation and understanding of the environment, weather and seasons. The cycles of land husbandry involving cutting, burning, rotational cropping and fallow periods in chitemene have shaped and sustained the local woodland ecosystem and enhanced soil fertility for subsistence crop farming.

\section{A scientific and technological reading of chitemene}

The ashen remains from the burnt biomass in chitemene raised soil $\mathrm{pH}$ by reducing acidity. The soil heat also raises soil $\mathrm{pH}$ by 1-2 units (Chidumayo, 1996). For example, we explored the consequences of controlled fires on soil nutrients, leading to an appreciation of the role and value of fire in the chitemene system. In our prescribed burning simulation experiment, the soil $\mathrm{pH}$ increased from an acidic condition of 5.84 to 7.15. A year later, the $\mathrm{pH}$ had reverted towards acidic soil conditions (Mwila, 2013; Phiri, 2014). The ashen remains contained important crop nutrients that included nitrogen, phosphorus, calcium, potassium and magnesium. Furthermore, we have observed some decreases in a number of heavy metal concentrations in the soil, such as copper and cobalt, following the prescribed burning. Overall, the ashen product from burning and chitemene thus improved soil suitability for crop farming (Chidumayo, 1996). Chidumayo (1996) observes that the ashen remains improve millet yields by, for example, raising the content of ammonium by nearly double. Further, the heat from the burning biomass kills the bacteria in the top soil, ensuring access to the soil's ammonium without competition from bacteria. Chitemene is thus an agro-practice from which it is possible to learn some principles of land husbandry (Thrupp, Hecht \& Browder, 1997). It is a mode of 
soil fertility management and a biomass-ash fertiliser system (Chidumayo, 1987, 1996); it serves as a mode of weed and pest control, and may help sterilise the soil by killing some microbes.

Chitemene is a form of organic farming where the ashen material from the burnt biomass serves as a natural fertiliser and lime that - unlike inorganic fertilisers such as urea and nitrate - tend to raise soil acidity. It is also an agro-practice that follows a crop rotation system, starting with non-leguminous crop millet. As the nutrients from the ash subside over time in the soil, the leguminous nitrogen fixing crops (i.e. groundnuts and beans) are grown in later years before the fallow period.

\section{Integration of chitemene knowledge and technologies in modern times}

Chitemene in present-day circumstances is experiencing a decline due to high population numbers and the subsequent pressure on land and forest resources (Chidumayo, 1996; Matthews, 2005). However, we agree with Trupp et al. (1997), who observed that 'the knowledge upon which shifting cultivation systems are based offers insights useful to agricultural development strategies'.

As described above, chitemene agriculture in the Miombo woodlands of Zambia is a good example of a socio-cultural process involving seasonal timing and soil fertility management in a stable high-rainfall area.This socio-cultural system has patterns of cultural mediation that extend to a cyclical process of around two decades before the cycle is repeated, from the clearing of the field, cropping and then the fallow period. Its basis for learning is direct observation and ecological experience in the environment and the ingenuity to create technologies that enable sustainable subsistence farming in an otherwise infertile soil system. One thus not only had the seasonal activities of around five years for the slash and burn tilling of a home area where children were born, but an extension of this to around 15-20 years. Here for the young to marry, they had to return to the lands of their birth, thereby enacting an extended fallow period for the forest to recover. This cultural cycle served to restore the ecological consequences of the slash and burn agricultural process that not only effected nutrient transfer from biomass to crop in leached forest soils, but also served to control soil pests with heat and smoke associated with the seasonal burning of arable land before planting with the arrival of the rains.

As the numbers of people increased and the forested areas shrank, the fundikila system of agriculture was developed as an adaptation of the chitemene system (Matthews, 2005). Fundikila (meaning to cover) is usually carried out in the fallow site of chitemene. There, mounds of grass are made in the field, covered by earth and then left to rot and decompose in the dry season. At the start of the next rains, the mounds are levelled and the planting of crops follows the order in chitemene, that is, millet and sorghum, and then legumes or groundnuts in later seasons. The fundikila system included seasonal variation in cropping that is now at the heart of the hybrid system that one finds in the same climatic region today as the onset of the summer season rains is now commonly delayed until December. Each successive adaptation has evolved to feed larger populations from the same resource base, but some of the early forest system is now fragmented and at risk. For example, chitemene could support two to four people per square kilometre; and the fundikila system is able to support 20-40 people per square kilometre (Mansfield et al., 1975, cited in Matthews, 2005). 


\section{Conclusion}

The chitemene and fundikila systems are biological methods of managing soil fertility and health, and thus their adaptations represent opportunities for intergenerational learning and sustainability. For example, in Zambia, experimentation in farming with ash and biomass charcoal ('biochar', created by burning biomass in limited air) is yielding promising results (Cornelissen, Martinse, Shitumbanuma et al., 2013). The biochar helps to retain potassium, calcium, magnesium, ammonium, thus reducing leaching. Biochar also appears to help improve the microbe population and microbial activity in the soil that helps in organic matter decomposition and nitrogen fixation in the soil.

This suggests that we cannot value people's traditional knowledge and technologies without unpacking their underlying rationales. In light of the rationale of shifting cultivation (such as in the chitemene system), Thrupp and colleagues (1997) proposed an integrated and interdisciplinary systems approach whereby socio-economic, political and agro-ecological factors affecting shifting cultivators are studied and implemented in development and environmental management programmes. This must be respectful of local knowledge and practices that have been resilient for millennia. In sum, the case study makes us appreciate socialecological systems and the fact that improved management of the environment and natural resources requires understanding the social and cultural relationships that already exist and working with the custodians of this intergenerational knowledge.

\section{About the authors}

Dr Overson Shumba is a Professor in the School of Mathematics and Natural Sciences and acting Director for the Centre for Academic Development at the Copperbelt University in Zambia. His research interests include mainstreaming Education for Sustainable Development and socio-cultural behaviours into science education so as to contextualise the subject, maximise its relevance and improve its quality.

Dr Felix Kanungwe Kalaba is a Senior Lecturer in the School of Natural Resources at the Copperbelt University, Zambia. He is an expert in the forest ecosystems of Africa and researches forests as socio-ecological systems.

\section{References}

Chidumayo, E.N. (1987). A shifting cultivation land use system under population pressure in Zambia. Agroforestry Systems, 5(1), 15-25. DOI:10.1007/BF00046411

Chidumayo, E.N. (1996). Ash-fertilisation for agriculture. In B. Campbell (Ed.), The miombo in transition: Woodlands and welfare in Africa (p. 45). Bogor, Indonesia: Centre for International Forestry Research (CIFOR). Retrieved from http://www.cifor.org/publications/pdf_files/ Books/Miombo.pdf.

Cornelissen, G., Martinse, V., Shitumbanuma, V., Alling, V., Breedveld, G.D., Rutherford, D. W., Sparrevik, M., Hale, S.H., Obia, A. \& Mulder, J. (2013). Biochar effect on maize yield and soil characteristics in five conservation farming sites in Zambia. Agronomy, 3, 256-274. Retrieved 
from http://citeseerx.ist.psu.edu/viewdoc/download?doi=10.1.1.361.4234\&rep=rep1\&ty pe $=$ pdf

Grogan, K., Birch-Thomsen, T. \& Lyimo, J. (2013). Transition of shifting cultivation and its impact on people's livelihoods in the Miombo Woodlands of Northern Zambia and Southwestern Tanzania. Human Ecology, 41(1), 77-92.

Matthews, R. (2005). Chitemene, fundikila and hybrid farming. The Zambian, 26 February. Retrieved from https://thezambian.com/2005/02/26/chitemene-fundikila-and-hybridfarming/

Mwila, F.L. (2013). Knowledge, attitudes, and practices of fire use in relation to climate change in Copperbelt Province of Zambia. Unpublished Bachelor of Environmental Engineering Thesis, Copperbelt University, Zambia.

Phiri, A. (2014). Fire management and climate change: Mitigation based on tracking fire prevalence in the Copperbelt and experimenting the impacts of prescribed fires on nutrient cycles. Unpublished Bachelor of Environmental Engineering Thesis, Copperbelt University, Zambia.

Thrupp, L.A., Hecht, S. \& Browder, J. (1997). The diversity and dynamics of shifting cultivation: Myths, realities, and policy implications. World Resources Institute Report. Retrieved from http://pdf.wri.org/diversitydynamicscultivation_bw.pdf. 


\section{Case study 3: South Africa}

\section{The Grasslands of Zululand and Nguni cattle cultures Sibongile Masuku}

Figure 6. The Ukahlamba landscape (left) and Bandlalenkosi Pearce (right), teaching a child how to apply medicative salve on a cow
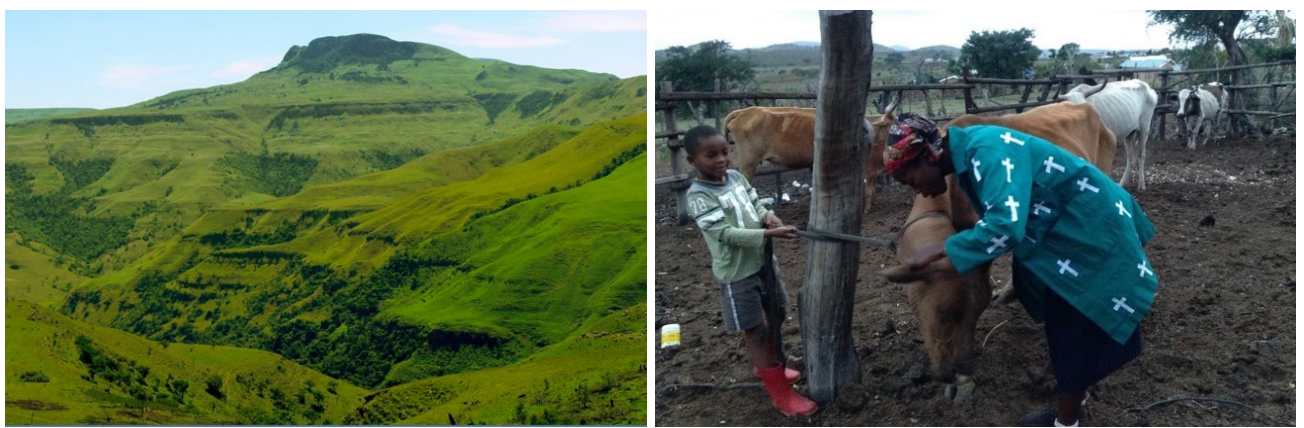

Historically, the grasslands of Zululand were sustained and expanded by the Nguni people, who used circular hunting and driving to clear the pastures of the wildlife that carried the dreaded nagana (sleeping sickness) cattle disease. Despite centuries of being herded in close proximity to the warmer riverine Lowveld where nagana and wildlife thrived, the Nguni cattle had little in the way of natural resistance to the disease. Like wild game, they had patchwork hides and white underbellies, however. This afforded them some protection against the tsetse fly-borne disease, which was transferred from infected wildlife by the blood-sucking flies landing on the shaded underside of their cattle. Young cattle herders had the knowledge to make dung fires to drive infected wildlife away. In his school diary, Magema Fuze (1859) noted and commented to Bishop Colenso that: 'When they came to the place of others [wildlife] they made fires and let it smoke on the cattle.' The combined effects of the cattle's patchwork colouring, the clearing of pastures through regular hunting and burning and the use of smoke successfully protected the cattle from the disease.

O'Donoghue (1998) uncovers how, as a result of these intergenerational knowledge practices, the landscape of Zululand was slowly transformed into grassland savanna and wooded riverine bush, where the reduced numbers of tsetse fly still managed to breed and from where they were transported into the cattle pastures by wild game. The colonial game laws forbade the Zulu from hunting and burning to maintain their pastures, creating untold suffering when the nagana cattle disease spiralled out of control in the late 19th century. The colonial government established fenced game reserves to separate cattle and game, but the reserves soon began to revert back to woodland, which didn't support the ungulates that used to roam the Zululand savanna. In the interests of attracting tourists, game wardens now began to burn the bush and grassland in order to retain the open mosaic landscape necessary for wildlife to thrive. They also had to develop culling (hunting) techniques to maintain game populations that could be supported by the available fodder. 
Today, when we look at how the landscape was transformed and sustained by the hunting and burning of the Nguni cattle culture - developed over centuries along with the African Nguni cattle - it is possible to observe patterns of biocultural interdependence that were invisible to the British colonial masters, who created the game parks attracting international tourists to Zululand today. The southern African landscapes were further transformed by fencing the cattle into paddocks where the cattle grazing reduced palatable fodder species, thus reducing grassland biodiversity. Limiting burning, which was considered destructive, encouraged bush encroachment, which further reduced the cattle's grassland fodder and encouraged the cultivation of smaller livestock like goats, which further degraded the Zululand pastures around nature reserves. Degraded rural landscapes now stand in contrast to the 'jewels in the crown' of the biodiversity conservation areas visited by tourists as the nature reserves of today.

Nowadays, in an attempt to improve the quality of natural grassland pasture, there is a return to cattle herding. It has been realised that human cultures create landscapes and that these landscapes can support the carefully managed cultural practices which produce the varied and various human livelihood practices across the landscapes of the world.

It is noteworthy that there are convergences and continuities cutting across O'Donoghue's (1998) and Masuku's (2018) research. Masuku's study of the relationship between people, livestock, the landscape and spirituality today highlights certain intergenerational relationships in some of the rural areas neighbouring the Hluhluwe-Imfolozi game reserve as well as in a communal area called Mpembeni. The Mpembeni communal area was ravaged by drought, seriously compromising the cattle's health and well-being. In Masuku's research, the local elders pointed out the relationship between cattle health, nagana and ticks, and how fire was not only capable of minimising the spread of nagana, but also killed the ticks that jumped onto the cattle and gave the herders tickbite fever as well. Masuku's study also revealed that some of the rituals associated with becoming a spiritual medium are linked to the cultivation of livestock. The researcher herself experienced a journey into spirituality with a teacher who could access the world of the living and the departed. This spiritual realm was revealed through trance dances and other visitations such as dreams. The spirit presence was celebrated with bloodletting from a goat, food and drink. Becoming one with the spirit also meant not eating certain parts of the cow. Through this example, Masuku shows that the intergenerational learning within certain communities extends beyond the immediately tangible into realms where wisdom can be accessed beyond what is local and perceived to be normal.

The social-ecological and spiritual dimensions of intergenerational learning are therefore evident in cattle as a medium of cultural expression. Here, the evidence of intergenerational learning displays socio-cultural dynamics typical in most communities that have been impacted by landscape changes as well as by more recent climate change, modernisation and diverse and demanding land uses. This has been exacerbated by the fact that the traditional cattle herders, the youth, now attended school. As the primary cattle herders, they learnt cattle herding and how to respond to environmental changes from their elder brothers, uncles, neighbours and fathers, who kept a watchful eye over them until they themselves were knowledgeable enough to share their skills with those younger than them. 
A traditional healer for livestock, Gama, described to Mausku how he is widely consulted and how his knowledge has grown to integrate that of commercial veterinary experts. His sons, who travel with him to homesteads where livestock are sick, are sent to collect the traditional medicinal plants critical for treating particular ailments. He proudly related how, when he was on one of his travels, his son of less than ten years of age had diagnosed a calf's sickness by himself and given it treatment. On his return, he found the calf was well on its way to recovery.

Masuku's study also focused on girls' roles in looking after livestock. She found that, in families with many boys, the girls were assigned the task of herding goats. Normally it was the younger boys who looked after the goats as an initiation into cattle herding.

In contrast, prescribed school curricula do not take into account learners' prior learning, experience and skills with regards to herding cattle. This omission creates a barrier of abstract detachment that children must then navigate in their early schooling. There is thus a need for the foundational learnings that come with taking responsibility for caring for cattle to be reflected in schooling.

\section{About the author}

Sibongile Masuku was at the time of authoring this case study a post-doctoral scholar at Rhodes University, and her work is mainly in cultural heritage resource management, intangible heritage, environmental education and creative writing.

\section{References}

Fuze, M. (1859). [1901]. Three native accounts of the visit of the Bishop of Natal to Umpande, King of the Zulus. In Colenso, J.W. (1982). Bringing forth light. Durban: Killie Campbell Africana Library.

Masuku, L.S. (2018). IN-BETWEENNESS: A postcolonial exploration of socio-cultural intergenerational learning through cattle as a medium of cultural expression in Mpembeni, KwaZulu-Natal. Unpublished PhD Thesis, Rhodes University, South Africa.

O’Donoghue, R.B. (1998). Detached harmonies: A study in/on developing social processes of environmental education in eastern southern Africa. Unpublished PhD Thesis, Rhodes University, South Africa. 


\section{Case study 4: India}

\section{Western Ghats of Kerala: Sacred forests, rice fields and gardens Unnikrishnan Payyappallimana}

Figure 7. The Western Ghats landscape is characterised by forests that were heavily deforested in colonial times. Despite this, there still remain sacred groves that have been retained and protected by local indigenous peoples.
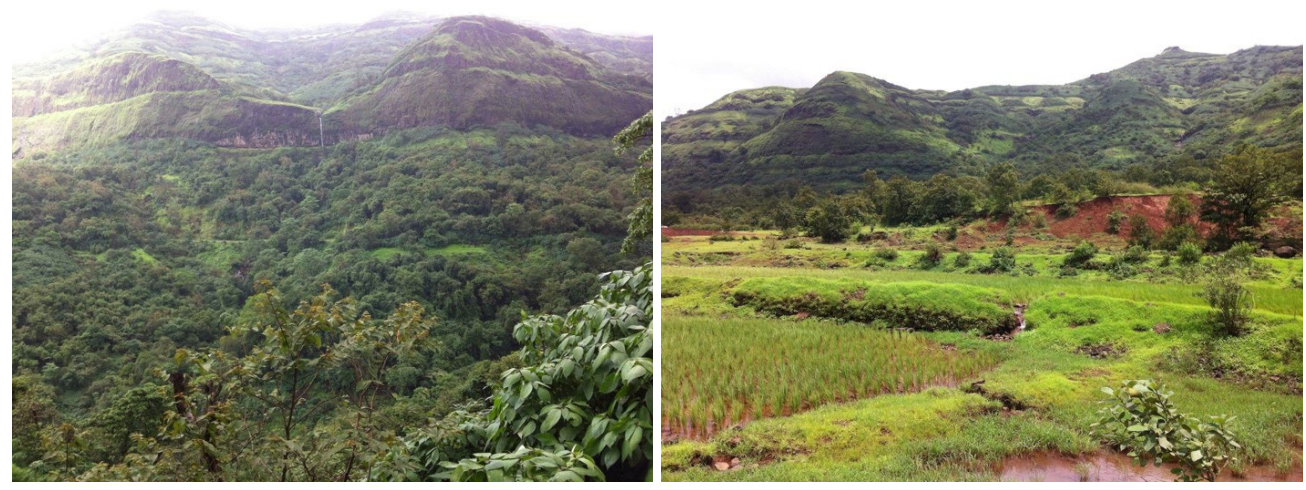

Source: Author

The monsoon seasonal cycle of the Western Ghats has resulted in trees evolving to survive droughts. To do so, they store nutrients in their leaves, which then drop to the forest floor as the hot dry season progresses. Soon the sacred groves have a thick carpet of leaves, which retains moisture and slowly turns into the humus/compost nutrients that will be washed out of the forests into the fields as the monsoon rains of the next season arrive.

For hundreds of years, the rice fields and gardens of the Western Ghat valleys of Kerala have produced rice and other foods, as well as nutritional and medicinal plants. Nutrients are naturally replenished from the forest groves, which produce humus-rich silt each season. The farmers channel water from the forests into their fields and gardens, where they produce compost and collect animal dung for fertilising their crops.

As a biodiversity-rich region, the State of Kerala has a long, well-documented history of homestead garden husbandry, which includes inventories of the numbers and characteristics of various species and their usage (Kumar \& Nair, 2004, 2006; Mohan, 2004; Mohan, Nair \& Long, 2007).A 14th century traveller, Shaikh Ibn Batuta, describes how

we came to the country of Malabar which is the country of black pepper. Its length is a journey of two months along the shore from Sindapur to Kawlam. The whole of the way by land lies under the shade of tree [...] and in all this space of two months' journey there is not a span free from cultivation. For everybody has there a garden and his house is placed in the middle of it; and around the whole of this there is a fence of wood, up to which the ground of each inhabitant comes. (Logan, 1981:86) 
The State of Kerala has rapidly urbanised in recent times, with the urban population increasing by $6.5 \%$ as large numbers of new towns have been established in the last decade. The region has 60 municipalities and five city corporations. However, even in the midst of urbanisation, several socio-cultural practices, including the dependence on home gardens, have continued. Households have knowledge of and use various plant resources for food, timber, firewood, spices, medicinal products, and spiritual and ornamental purposes.

With respect to the usage of plants for medicinal purposes, a study conducted in a central district of Kerala found that homestead gardens contain around 153 species, with an average number of 36 medicinal plants in such gardens (Mohan et al., 2006). The landscapes and gardens of Kerala have thus nurtured a highly evolved traditional medical culture. Testimony to this usage of a unique, locally sourced pharmacopoeia is its codification in a vast textual literature in vernacular from $1500 \mathrm{CE}$, as well as the distinctive treatment approaches among Kerala's contemporary physicians. The knowledge has also been well documented in modern medico-botanical documents in Latin such as the Hortus Malabaricus, compiled between 1674 and $1703 \mathrm{CE}$. On one hand there are specialised healing traditions such as these, but on the other, there is also the general household home-garden knowledge, which has been used for preventive, curative and promotive purposes for simple primary healthcare problems, such as fever, upper respiratory tract infections, gastro-intestinal problems (e.g. diarrhoea), dysentery, worm infestations, hepatitis, anaemia, arthritic conditions and certain gynaecological conditions.

In the well-known Kerala Ayurveda medical tradition, the majority of the formulations commercially produced across the state (around 500 of them) are based on this specialised local pharmacopoeia and the use of local resources. Of the 4680 identified plant species in Kerala, 900 are reported to have medicinal value. Around 400 medicinal plants are used by around 700 active pharmaceutical industries, of which 230 are used widely. Of these, over $75 \%$ of medicinal resources are available locally, thus indicating a strong link between the pharmacopoeia and local biodiversity (Payyappallimana, 2010).

Regarding food resources, 142 crops belonging to 43 plant families and 104 genera are grown in these agro-biodiverse systems (Nayar, 2011). Homestead gardens alone host 118 to 128 species, with each garden having between 34 to 38 species. These systems are sustained as a result of biophysical advantages, the conservation of biocultural diversity, product diversification, the non-market values of products and services, and various social and cultural values, including the potential for gender equity in managing the systems (Kumar \& Nair, 2004).

The Kerala Land Reforms Act of 1963 redistributed surplus land to landless farmers, and was successfully implemented in the 1970s and 1980s (Guillerme, Kumar, Menon et al., 2011). While this event has been criticised for its negative impact on agri-biodiversity, it has nevertheless had positive impacts in terms of the better use of unused land and stronger landholder participation in land management.

In addition, the Kerala Panchayati Raj and Municipality Act of 1994 formed the basis for decentralised governance, and a peoples' campaign for decentralised planning was organised in the following years. These decentralisation policies, community mobilisation and training in Kerala State have had a positive overall impact on garden development and the maintenance of biocultural diversity. 


\section{About the author}

Unnikrishnan Payyappallimana notes that healthy ecosystems and biocultural diversity nurture life on Earth and enhance human health and well-being. He currently works at the interface of science-policy and practice in the context of health systems, biodiversity and traditional knowledge in ensuring equitable access to health in local communities.

\section{References}

Guillerme, S., Kumar, B.M., Menon, A., Hinnewinkel, C., Maire, E. \& Santoshkumar, A.V. (2011). Impacts of public policies and farmer preferences on agroforestry practices in Kerala, India. Environmental Management, 48(2), 351-364.

Kumar, B.M. \& Nair, P.R. (2004). The enigma of tropical home gardens. Agroforestry systems, 61(1-3), 135-152.

Logan., W. (1981). Malabar manual.Volume 1.Thiruvananthapuram: Chitra Publications.

Mohan, S. (2004). An assessment of the ecological and socio-economic benefits provided by home gardens: A case study of Kerala, India. Unpublished PhD Thesis, University of Florida, USA.

Mohan, S., Alavalapati, J.R.R. \& Nair, P.K.R. (2006). Financial analysis of home gardens: A case study from Kerala State, India. In B.M. Kumar and P.K.R. Nair (Eds), Tropical home gardens: A time-tested example of sustainable agroforestry (pp. 283-296). Netherlands: Springer.

Mohan. S., Nair, P.K.R. \& Long, A.J. (2007). An assessment of the ecological diversity of homegardens: A case study of Kerala State, India. Journal of Sustainable Agriculture, 29(4), 135-153. DOI:10.1300/J064v29n04_10

Nayar, N.M. (2011). Agro-biodiversity in a biodiversity hotspot: Kerala State, India. Its origin and status. Genetic Resources and Crop Evolution, 58(1), 55-82.

Payyappallimana, U. (2010). Traditional medicine in health system development: A case study of Kerala State, India. Yokohama Journal of Social Sciences, 15(3):77-101. 


\section{Case study 5: Sweden}

\section{East Vättern Scarp landscape and sustainable meadow fodder Asa Westermark and Mikael Gustafsson}

Figure 8. Sweden's early village homesteads were at the centre of meadow pastures in the forested landscape. Today, the Swedish rural landscape is still, in part, characterised by open pastures and fields on sunny, south-facing slopes.
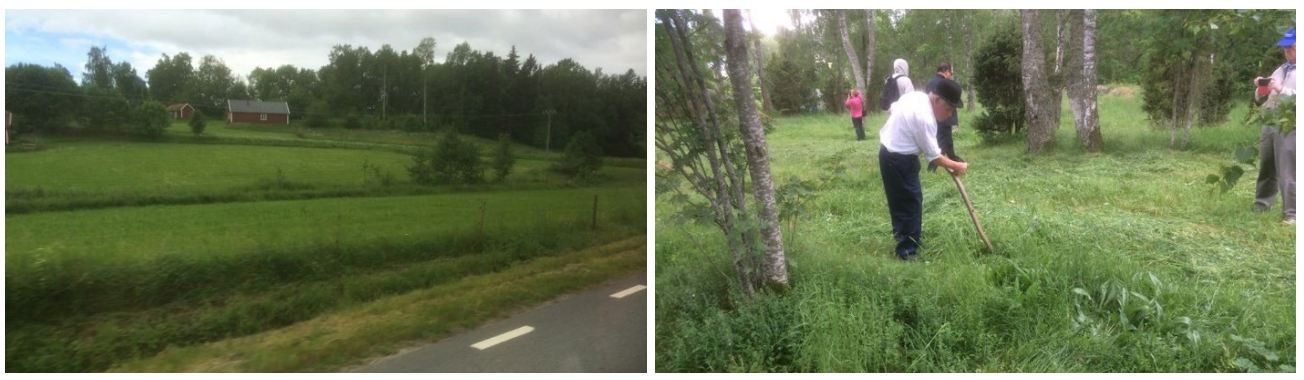

Figure 9. Landscape of meadow pastures. This type of agrarian landscape management is characteristic of most northern European countries. What is interesting about the East Vättern Scarp landscape around Jönköping are the processes of environmental, social and cultural interactions responsible for the creation of the mosaic landscape over centuries. Traditional landscape management has been preserved; and the diversity of fodder plants in the summer pastures has been maintained and is still visible in the landscape today.

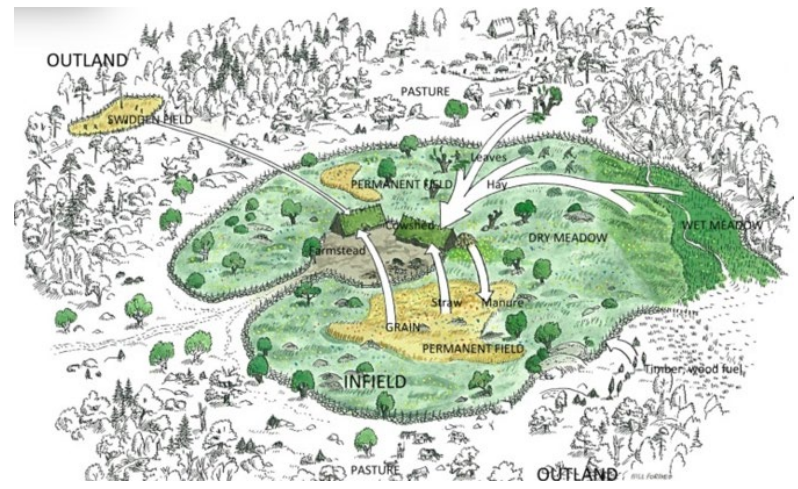

Source: Handout: East Vättern Scarp Landscape Biosphere Reserve, Sweden

The Swedish case builds upon the concept of 'processual landscape' introduced by Torsten Hägerstrand in the 1990s (Hägerstrand, 1993). The processual landscape is dynamic and shaped over time through the interaction between man and nature. The East Vättern Scarp is an example of how traditional management of meadow pastures has been preserved by adapting to physical geographic conditions, and thereby also sustaining diverse land use. Over time, ecological and social well-being have been mutually supported and maintained. 
In Figure 10, the diagram on the left shows the landscape from a static point of view. Here, the scenery represents a view of the outcome of processes of change. The diagram on the right describes the processual landscape in terms of the actual processes of change that have contributed to the outcome. These processes of change comprise the natural, social and cultural dimensions that interact over time and in space.

Figure 10. Static and processual landscape views
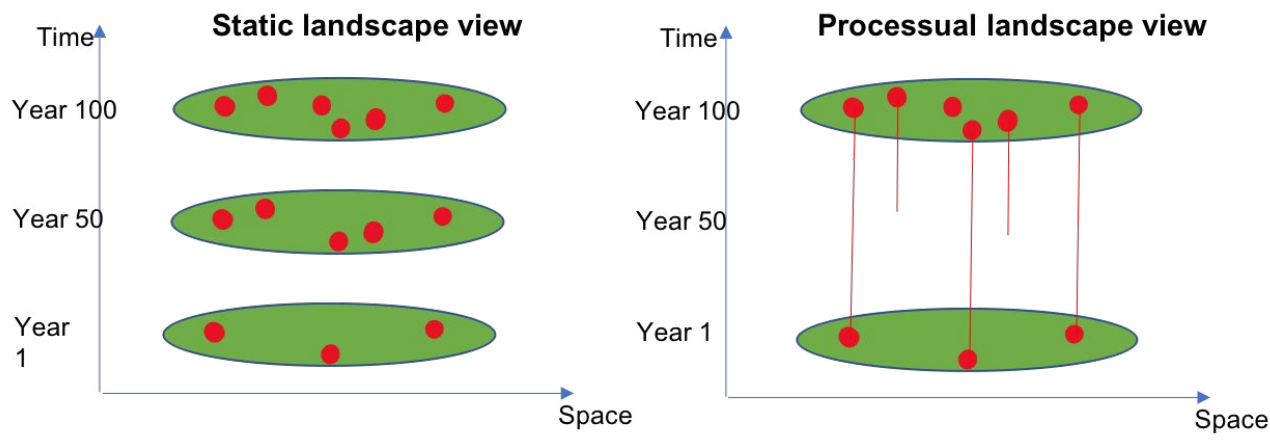

Source: Modified from Hägerstrand (1993:39)

The physical and geographical factors in the East Vättern Scarp landscape are important factors for this long-lasting traditional way of managing the land. In the Scarp and its vicinity, the topography is uneven, and rocky hills with thin soil depth alternate with small valleys with greater soil depth. This kind of terrain causes problems for modern mechanised agriculture. As a result, the area still has a large proportion of relatively small farms, and it is common for the landowner to have more than one source of income, such as agriculture, forestry and other forms of labour. This situation has contributed to the preservation of diversified land use linked to various cultural and social activities.

In the East Vättern Scarp landscape of today, old deciduous trees can be found that bear the traces of hamling from the past. These traces occurred when farmers harvested branches with twigs and leaves as winter food for their cattle. The farmers also harvested grass from the meadows for the same purpose. During summer, the cattle grazed on pastures as well as in the nearby forest. The best soil was used for the cultivation of potatoes and cereals. The manure that the animals produced in pastures and stables was used on the fields to grow crops. In the past, it was said that 'the meadow is the mother of crop fields'. In such meadows and pastures, there are biodiverse herb flora, which in today's modern agricultural landscape is increasingly rare. Hamling was generally common in southern Sweden until the beginning of the 20th century. Nowadays, this technique of caring for trees is mostly used for cultural purposes and to maintain biodiversity.

At one site in Kabbarp, near the town of Gränna, the endangered elder-flowered orchid (Dactylorhiza sambucina) is found (see Figures 11 and 12). This species has been preserved in this area specifically as a result of the meadow and the pasture it offers and, hence, serves as an example and indicator of the important role that this type of environment, in combination with the hamling technique, has played in the past - and can therefore also play in the future. 
The elder-flowered orchid has inhabited this site since at least 1887 (Edqvist, Karlsson \& Christoffersson, 2007). In the map below from 1809, it is obvious that land use was similar then, with meadows and pastures in almost the same places as today, and so it is very possible that the orchid grew there 200 years ago. According to Gustafsson's experience from in vitro propagation (Inghe \& Tamm, 1988), it takes at least five years for a seed to become a mature plant and, as a result, the species spreads very slowly; however, the plant can grow for more than 40 years.

Figure 11. Map of the Kabbarp property from the year 1809. Meadow and pasture is greenish and cultivated fields are yellowish brown. In the 'Hill meadow' and the 'East of Kabbarp meadow', red circles and ovals indicate where most of the elder-flowered orchid (Dactylorhiza sambucina) grows today.

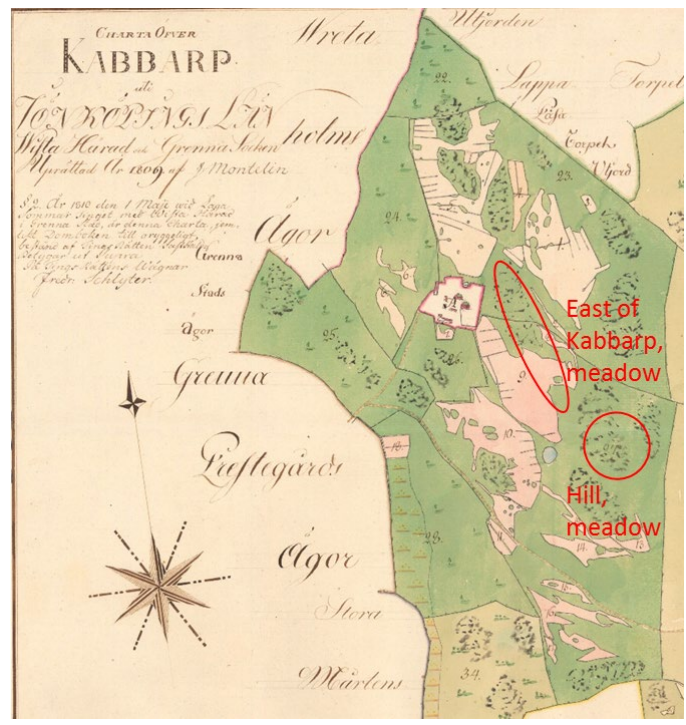

Source: Lantmäteriet. (2018). https://www.lantmateriet.se/

The biosphere reserve of East Vättern Scarp provides insight into the old farming landscape, which in most cases has undergone major changes over the last 50 to 60 years. Today, most pastures in Sweden are planted with forest, or are fertilised pastures producing monocultures. However, in the biosphere reserve, traditional practices have been preserved, and pasture diversity has been maintained accordingly. Harvesting takes place after the annual seed drop, ensuring that the seeds for the next season are already in the ground and ready to germinate after the cold winter season when pastures are covered with snow. To date, the specific shape of the landscape and the traditional farming practices have fruitfully combined economical and sustainable agriculture with ecological sustainability. The purpose of land use has changed over time, from the livelihoods of the past to farming, and then to the preservation of the environment and biodiversity. This transformation will continue, giving way to new opportunities, such as tourism, and, in this manner, the aesthetically beatiful landscape will be passed on to future generations. 
Figure 12. Kabbarp farm and elder-flowered orchid (Dactylorhiza sambucina)

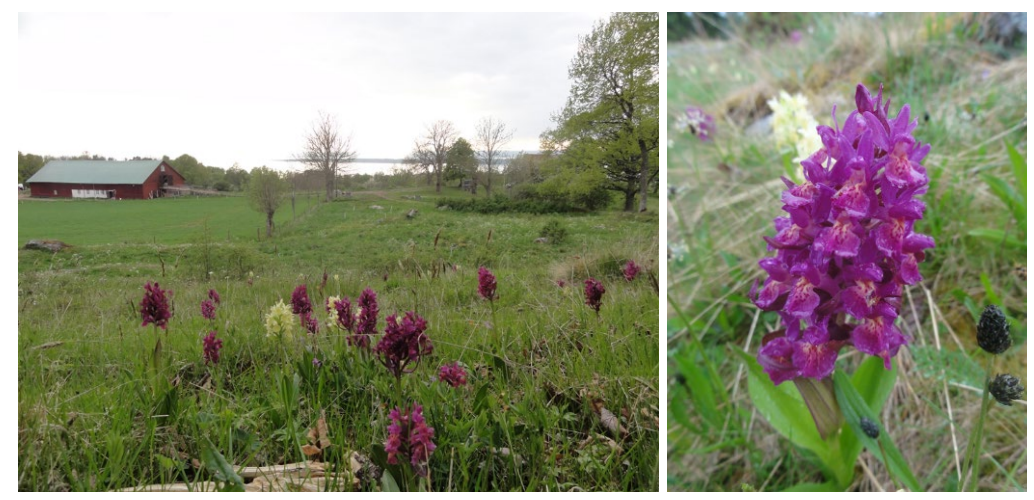

\begin{abstract}
About the authors
Åsa Westermark is a Senior Lecturer in Human Geography at the School of Education and Communication at Jönköping University, Sweden. Her research interests are in the areas of geography didactics for sustainable development, applying and exploring contextual learning from everyday life, and time-geographic analysis.
\end{abstract}

Mikael Gustafsson is a Senior Lecturer in Earth Sciences at the School of Education and Communication at Jönköping University, Sweden. His research interests are in the areas of geography didactics for sustainable development and how traditional land-use affects and promotes biodiversity.

\title{
References
}

Edqvist, M., Karlsson, T. \& Christoffersson, J. (2007). Smålands flora. [Bd 2] Föreningen Smålands flora. Uppsala: SBF-förlaget.

Hägerstrand, T. (1993). Samhälle och natur, in Region och Samhälle, Nordrefo, 1, 9-59.

Inghe, O. \& Tamm, C.O. (1988). Survival and flowering of perennial herbs. V. Patterns of flowering. Oikos, 51, 203-219.

Lantmäteriet. (2018). https://www.lantmateriet.se/ 


\section{Post Script - Learning and change}

Starting points: From sharing knowledge in context to deliberating abstract propositions The ways in which we learn as individuals and in the company of others in the intergenerational, social-ecological landscapes within which we have grown up are clearly diverse. They are also expanding in modern times with the advent of moving images and social media. In his treatise on the sociology of increasingly reality-congruent knowledge, Norbert Elias (1987:64) noted that

[t]he method which people use in acquiring knowledge is functionally interdependent with, and thus inseparable from, the substance of the knowledge they possess, and especially from their basic image of the world.

This perspective on social learning resonates with the rich diversity of intergenerational knowledge being carried forward and being changed amongst people living within the socialecological landscapes depicted in the case studies. It also points to an unfortunately oppressive mechanism of alienation in colonial modernity where the situated intergenerational knowledge that peoples possessed was commonly marginalised and displaced by alienating abstract propositions within modern curricula designed to shape and change behaviour.

It is thus not surprising that many students today are beginning to question and challenge the received curriculum as alienating and irrelevant. The strategies of resistance and inclusive change have been many and varied. On the international stage, the UN Secretary General's Scientific Advisory Board (UNESCO, 2016:2) has exemplified cultural diversity, noting, in line with Elias (1987 above) that: 'The cultures and values of peoples, and the knowledge and innovation within societies are fundamental cultural resources and building blocks for problem-solving and solutions.'

On the curriculum front, there has been a proliferation of new curricula that have been designed to be ethnically explicit. There is also an emphasis on mainstream state curriculum innovations that are attempting to be more plural and inclusive. Neither trajectory of curriculum reform is proving to be wholly satisfying and the terrain of modern education remains fractured and contested as we search for a perspective that is likely to enable situated dispositions and reflexive change in changing worlds.

\section{Working with images and story as 'foundations for awakening ideas'}

The intergenerational descriptions in the case studies all start with memory-evoking images and, from an insightful situating of these, expand to learner-led narratives of how intergenerational knowledge practices have shaped landscapes and people over generations. In this way, they provide no more than starting points towards generating 'foundational knowledge for an awakening of ideas'. ${ }^{1}$ Working with situated stories and photographic images as starting points for learning together allows people to recognise land that is theirs. Here we can see ourselves surrounded by what we recognise and come to know, and we value things together and in diverse ways. What we come to know and value makes us who we are, with the competence to act in ways that might best provide for us and our families, friends and communities. 
We have found that intergenerational stories and photographic images can be very effective starters for ESD conversations. The images invite participants to develop the competence to share their thoughts and to develop internal conversations around their experiences, observations and dispositions. In this way, developing conversations can signify what is important to people and they can build on what is experienced and already known. Here information is shared in the process of reviewing images (simulations and photographs or sketches) through a methodological process of eliciting responses (Harper, 2002) and deliberative learning.

Deliberative learning processes such as this can simply develop from what is recognised. Interestingly, recognition can apply to both contexts that are known (own land) and contexts that are new (others' land). Here images of a known landscape normally evoke accounts of identity and lived experiences as well as respect for the difference of others in different parts of the world. The unknown landscape (the new) can develop through comparative narratives that point to similarities and differences (how our place is similar or different). In this way, intergenerational narratives, photographs and pictures can be great conversation starters for learning transactions, opening up deliberative knowledge sharing. With experience and starting with narratives and photographs that participants bring to learning interactions, it is possible to build competences for ESD processes of deliberative learning as an open-ended human universal value.

\section{Competence to recognise, value and act as a human universal in cultural contexts}

In line with this, competence in ESD, refers to the knowledge, dispositions and a capacity to act together in ways that enable participants to recognise things, assess value and act on emerging matters of concern (Schreiber \& Siege, 2017:91). Feldman Barrett (2017) reports how the cognitive sciences have recently mapped how humans function in the world through predictive simulations that enable us to constitute and mediate our emotions. In exploring the making of our emotions, she describes (2017:153) how: 'Your brain issues a storm of predictions, simulates their consequences as if they were present, and checks and corrects those predictions against actual sensory input.' She also notes (2017:66) how

through continual prediction [in the mediating company of others], you experience a world of your own creation that is held in check by the sensory world. Once your predictions are correct enough, they not only create your perception and action but also explain the meaning of your sensations. This is your brain's default mode. And marvellously, your brain does not just predict the future. It can imagine the future at will. [Brackets added.]

Time and again we have found that the imaginaries evoked in story sharing, the simulations in the form of pictures, along with mimicry and mime, resonate with and evoke internal conversations where participants can share what they recognise, value and act on to constitute their worlds. In this way, we have come to work with pictures and stories of knowledge practices for inviting participants to share what they recognise, value and do. An emerging theme is inviting participants to identify and exemplify intergenerational ecologies of knowledge as starting points for reflexive enquiry. The deliberative learning processes that emerge resonate 
within the social-ecological landscapes of change examined in this study. There is thus still hope for better situated and more collaborative learning as we strive to reimagine better ways of living and learning together in intergenerational worlds of possibility that offer more just and sustainable futures in a changing world.

\section{Endnote}

1. A sense of the importance of intergenerational knowledge practices as foundations for sensing, identifying, situating, expanding and awaken deep ideas was pointed to by many of the case study writers and was vividly expressed by Mikael Gustafsson in this way.

\section{References}

Elias, N. (1987). Involvement and detachment. London: Basil Blackwell.

Feldman Barrett, L. (2017). How emotions are made: The secret life of the brain. London: MacMillan. Harper, D. (2002). Talking about pictures: a case for photo elicitation. Visual Studies, 17(1), 13-26.

Schreiber, J. \& Siege, H. (2017). Curriculum framework: Education for Sustainable Development. Bonn: Engagement Global.

UNESCO (United Nations Educational, Scientific and Cultural Organization). (2016). Indigenous and local knowledge(s) and science(s) for sustainable development. Policy Brief by the Scientific Advisory Board of the United Nations Secretary-General, 5 October 2016. 